\title{
La Minería Urbana. Un análisis desde el ordenamiento jurídico en Cuba. Una Apuesta al
} Desarrollo Sostenible desde la Economía Circular

\section{The Urbane Mining. An Analysis from the Juridical Organizing in Cuba. A Bet to the Sustainable Development from the Circular Economy}

\author{
*Alcides Antúnez Sánchez ${ }^{1}$ y **Ilianys Matos Guerra², Rosa María Álvarez Valerino ${ }^{3}$ \\ IProfesor Auxiliar Derecho Ambiental y Derecho Internacional. Facultad de Ciencias \\ Económicas y Sociales. Universidad de Granma. República de Cuba \\ ${ }^{2}$ Asesora Jurídica de la Dirección Provincial del Ministerio de Trabajo y Seguridad Social. \\ Provincia Granma. República de Cuba. \\ ${ }^{3}$ A.A. carrera de Derecho. Facultad de Ciencias Económicas y Sociales. Universidad de \\ Granma. República de Cuba \\ *aantunez@udg.co.cu,**ilianys.mguerra@nauta.cu
}

Fecha de recepción: 08/12/2019

Fecha de aceptación: 15/05/2020

Publicado: $30 / 06 / 2020$

\section{Resumen}

La constante innovación tecnológica y la cultura de consumismo hacen que las personas cada vez más quieran sustituir los aparatos eléctricos y electrónicos que utilizan por otros más avanzados, lo cual genera que cada año la basura electrónica incremente. Se busca que los residuos electrónicos, no terminen en un vertedero o incinerador, y que más países se unan al buen manejo y tratamiento final a través de la economía circular. La irrupción de la Revolución Científico Técnica y el proceso de internacionalización y de liberalización mundial, ha sido el suceso que ha originado nuevos desafíos políticos, económicos, culturales y sociales a los Estados. Ha traído consigo de forma lenta los paradigmas que caracterizaban a la sociedad industrial, y han ido cambiando al ritmo que ha marcado las continuas irrupciones en la innovación, apoyadas en la tecnología computacional y en la telemática en la 4ta Revolución Industrial. Surgen nuevos productos, nuevos servicios públicos, nuevos modelos de negocios, nuevas necesidades, nuevos retos que en definitiva cuestionan el formato y las claves 
competitivas de la industria del futuro, en continua construcción y evolución en un mundo global en el siglo XXI, donde "lo verde vende".

Palabras clave: desarrollo sostenible, economía circular, minería urbana, ordenamiento jurídico.

\begin{abstract}
The constant technological innovation and the culture of consumerism do that people more and more want to substitute the electric and electronic apparatuses that they utilize for more advanced others, which generates than each year the electronic trash increment. One searches than the electronic residues, do not end up in a drain or cremator, and what else countries join up to the good handling and final treatment through the circular economy. The invasion of the Scientific Technical Revolution and the process of internationalization and of worldwide liberalization, it has been the event that has originated new political, cost-reducing, cultural and social challenges to the States. You have brought along the paradigms that were characterizing to the society industrial of slow form, and they have gone changing the rhythm that you have dialed continuous invasions in the invention, backed up in the computational technology and in the telematics in the 4ta Industrial Revolution. New produces, new public services, new models of business, new needs, new challenges that definitively the format and the competitive keys of the industry of the future, at continuous construction and evolution in a global world in the century question XXI, where what's green sells happen.
\end{abstract}

Key words: Sustainable development, circular economy, urban mining, juridical organizing.

\title{
Introducción
}

Desde los inicios de la Revolución Industrial, se aprecia como las prácticas y los avances tecnológicos han impactado en los hábitos de consumo y producción del hombre como ser social, pero también en el medio ambiente de una manera sin precedentes afectándolo de manera negativa. Actualmente, el problema ambiental ha derivado en lo que se conoce desde la 
palestra internacional como desarrollo sostenible desde el pasado siglo $\mathrm{XX}$, donde se propone que los sistemas sociales y ambientales tengan la misma importancia que los sistemas económicos, provocando un cambio de paradigma que invita a analizar las formas de gestión en cómo las economías pueden producir y consumir bienes y servicios amigables con el ambiente, lo que les permitirá ser más competitivas.

En consecuencia, se valora como el desplazamiento forzado por los desastres naturales, el cambio climático, el agotamiento acelerado de los recursos naturales, la pérdida de la biodiversidad, la contaminación ambiental son algunos de los grandes retos a los que se encuentra enfrentada la humanidad en la actualidad desde el punto de vista ambiental, al decir desde sus estudios por LEFF. ${ }^{1}$

Desde la perspectiva jurídica, sobre la extracción de recursos naturales es posible hablar de una crisis del Derecho Ambiental y dentro de este al Derecho Minero, a través de la flexibilización de la normatividad jurídica. Para ello, se analiza como la crisis ambiental se representa en normas que contrario a los mandatos constitucionales y legales de protección del ambiente, se reproducen progresivamente hacia el deterioro ambiental, a la extracción de minerales e hidrocarburos y a la vulneración de los derechos humanos de comunidades urbanas, rurales y de grupos originarios.

Hacen ya más de 30 años desde el pasado siglo XX, se acuñará una expresión que representaría una revolución en el mundo, al menos desde una dimensión teórica, en la conciencia de la sociedad del momento, en la protección jurídico-política al medio ambiente y en las bases del sistema socio-económico mundial, conocido como el desarrollo sostenible. La esencia que propone es buscar un adecuado equilibrio entre el desarrollo económico y la protección del medio ambiente, de tal forma que, como se explica en el citado informe, se

${ }^{1}$ Leff, E. et al. (1991) Las ciencias sociales y la formación ambiental a nivel universitario en América Latina. UNESCO, México. 
satisfagan las necesidades de las generaciones presentes, sin comprometer la capacidad de las

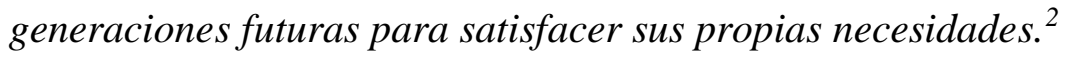

Uno de los últimos pasos de esta evolución en la protección del ambiente, es lo que hoy se le conoce como economía circular (EC), como el método que busca no sólo una producción sostenible, sino un consumo responsable, que a criterio de los autores está vinculada con la empresa responsable. Como respuesta a este progreso, una nueva economía ecológicamente racional, ecoeficiente e inclusiva, la cual actúa sobre las causas fundamentales de los desequilibrios; es pertinente significar sobre las actuales pautas económicas no solo de producción y consumo, denominada "economía verde", ha constituido un eje fundamental en la Conferencia de la Naciones Unidas sobre el Desarrollo Sostenible de 2012 (Cumbre de Río +20) tal como ha quedado plasmado en su documento denominado "El Futuro que Queremos".3 Se procedió para abordar el tema, partir de la revisión de la literatura científica, sustentada en dos criterios, el primero por temas como se desarrolla y el segundo de lo general a lo particular; se revisó la bibliografía jurídica especializada en materia de Derecho Constitucional, Administrativo y Ambiental. Dentro de ello, la minería urbana, la economía circular, el régimen de concesiones de recursos naturales por la multidisciplinariedad y transdisciplinariedad del tema. Lo que permitió realizar acciones de capacitación de posgrado a los consultores jurídicos de la Empresa Provincial de Servicios Legales en Granma, bajo el financiamiento del proyecto empresarial suscrito entre esta empresa y la Universidad de Granma en el año 2020 en cumplimiento de los Objetivos del Milenio para el 2030.

\section{Marco teórico}

${ }^{2}$ Consúltese, Piñar Mañas, J. (2003) El desarrollo sostenible como principio jurídico, Estudios de Derecho Público económico, Madrid, pp.185-204; Juste Ruíz, J. (2005) El Desarrollo Sostenible y los Derechos Humanos, Protección Internacional de los Derechos Humanos: Nuevos desafíos, Editorial Porrúa, México, p. 333

${ }^{3}$ Brundtland, G. (1987) Informe Nuestro futuro Común, ONU.

Cienc. Soc. y Econ. UTEQ. 2020. 4(1): 109-153 112 
El artículo realiza una caracterización del ordenamiento jurídico cubano de la minería urbana, a partir del texto constitucional y su desarrollo normativo desde el Derecho Administrativo Ambiental desde la pertinencia del principio jurídico del desarrollo sostenible y su evolución a la economía circular. Está sustentado en el Proyecto Empresarial para la capacitación de posgrado en la Empresa Provincial de Servicios Legales en la provincia Granma desde el 2020, con la carrera de Derecho de la Universidad de Granma Para ello, han sido utilizados como métodos de la investigación: el histórico lógico, análisis síntesis, inducción deducción, y la revisión bibliográfica.

\section{La Minería Urbana o Inversa. Origen, concepto y desarrollo}

En el siglo XX, ante la constante innovación tecnológica y la cultura de consumismo hacen que las personas cada vez más quieran sustituir los aparatos eléctricos y electrónicos que utilizan por otros más avanzados, lo cual genera que cada año la basura electrónica se incremente. El reciclado de los residuos de los aparatos eléctricos y electrónicos o como se le denomina "Minería Urbana", se aprecia que en el siglo XXI para los países tiene un doble impacto positivo, su uso está demostrado toda vez que permite recuperar metales o materiales que son cada vez más escasos y cuya obtención es de relevante importancia.

La mayoría de los productos electrónicos están hechos por sus fabricantes de recursos valiosos, como los metales preciosos, plásticos y el vidrio. Muchos requieren energía desarrollada y los recursos de fabricar. Sin embargo, cuando los equipos electrónicos se destruyen, todos estos materiales valiosos también se descartan. En última instancia, generan más contaminación, ya que requiere que todos los nuevos recursos se utilicen para la fabricación de nuevos productos electrónicos.

Gómez desde su postura valora “...la minería urbana del término acuñado en los últimos años como Urban Mining (UM) como todas las actividades y procesos relacionados 
con la recuperación de compuestos, energía y elementos de productos, edificios y residuos generados a partir de ciclos urbanos..."4

Cuando se habla de la minería, se valora cómo se pondera el aprovechamiento de todos los minerales e incluso a los hidrocarburos a través de un conjunto de etapas, es decir, la minería, es el proceso de explotación integrado que va desde la búsqueda de las sustancias mineras hasta su venta como materia prima al consumidor final. Se demuestra en este sentido que, a través de la minería urbana se genera un alto impacto ambiental y social, y al mismo tiempo se frena el impacto que estos residuos agresivos generan en el ambiente al degradarse en los basureros o rellenos sanitarios, contaminando con ello las fuentes de agua, los suelos y el aire.

Por consiguiente, se justiprecia como la actividad de la minería urbana requiere de un conocimiento adecuado acerca del proceso metabólico de los materiales dentro de los sistemas urbanos para poder planificar en el tiempo y el espacio de su momento de salida, potencial, reuso o reciclaje inmediato o posterior ante la obsolescencia programada de los equipos electrónicos tirados a la basura por quienes la ejecutan en las ciudades.

Demanda, entonces a criterio de los articulistas que, para quienes se ocupan de realizar la minería urbana el manejo precautorio y planificado en el tiempo y el espacio, considerando cantidades, cualidades y complejidad de los residuos (en términos de las sustancias que los componen); además de una perspectiva distinta al típico manejo de residuos que se ocupa de gestionar los flujos inmediatos de residuos de manera lineal, procurando en un grado u otras ciertas medidas de reciclaje y recuperación de materiales y de energía incorporada (vía incineración, u otros mecanismos).

En este sentido, se considera que los medios de comunicación con el uso de las TIC revelan la preocupación y efectos a nivel mundial que está causando el calentamiento global,

${ }^{4}$ Gómez, J. (2018) Minería Urbana: Recuperación de Metales y Elementos Estratégicos de Ciclos Urbanos. Tesis de Grado Ingeniero Industrial. Universidad de Barcelona. España.

Cienc. Soc. y Econ. UTEQ. 2020. 4(1): 109 - 153114 
cambio climático, enfermedades y virus que se originan por nuevos impactos ambientales, cuyos factores, entre otros son la contaminación ambiental que se produce por desarrollo de la tecnología, industria, fertilizantes, fungicidas, a través de las redes sociales en este siglo XXI. De aquí que se preconice, sea una necesidad estar capacitado en temas vinculados a esta actividad riesgosa a la salud humana, a causa de contener esta basura electrónica sustancias tóxicas tales como plomo, mercurio, cadmio, berilio; entre otros químicos peligrosos agresivos al hombre, es el papel de relevancia de la formación jurídico ambiental por la academia para desarrollar competencias profesionales. ${ }^{5}$

Con ello se justiprecia su vínculo con el Derecho Ambiental y sus principios que lo informan como el precautorio, prevención, responsabilidad, y legalidad, entre los de mayor pertinencia. Aunque, otro principio vinculado al tema es el principio de la Responsabilidad Ampliada del Productor exige que los fabricantes acepten la responsabilidad de todas las etapas del ciclo de vida de un producto, incluida la gestión del final de su vida útil, de aquí la necesidad de cumplir con el principio de legalidad a través de cuerpos jurídicos que desde el Derecho Público lo establezcan. ${ }^{6}$

Empero, para nadie es secreto que la era electrónica-digital llegó para transformar nuestras formas de vivir, ha impactado, no sólo en el modo de comunicarnos, sino que, también en el cómo, cuándo y dónde nos relacionamos, educamos, trabajamos y hasta en el uso de nuestro tiempo libre. Esta era está caracterizada por su evolución frenética tanto en el software

\footnotetext{
${ }^{5}$ Véase para profundizar, Novo, M. y Murga, M. (2010) Educación Ambiental y Ciudadanía Planetaria. Revista Eureka sobre Enseñanza y Divulgación de las Ciencias. $\mathrm{N}^{\circ}$ Extraordinario, España, pp.179-186; Molano, N. (2014) La formación ambiental en la educación superior: una revisión necesaria, Revista Luna Azul, N 39, Colombia, pp.186-206.

${ }^{6}$ Confróntese, Cafferatta, N. (2004) Los principios y reglas del Derecho Ambiental. PNUMA. El Salvador; Caferrata, N. (2009) Teoría de los principios del Derecho Ambiental, Revista Abeledo Perrot, Argentina.
} 
(programas y soporte lógico) como el hardware (aparatos y dispositivos), los que evolucionan en todo momento. ${ }^{7}$

Se aprecia de esta manera, cómo se origina por la práctica llevada a cabo en muchos países, con la finalidad de reciclar los aparatos eléctricos y electrónicos, incluyen estos en su interior sus componentes, piezas o cables elaborados con materias primas las que son reciclables, aquí es donde entra a jugar su rol la minería urbana. Hay que señalar que ya algunos de estos materiales empiezan a ser hoy en día un bien escaso en el planeta, mientras que en otras ocasiones por el alto valor que están alcanzando en los mercados se ha fomentado la actividad de la minería urbana, como la base del modelo económico: la provisión de materiales para abastecer la incesante demanda de la sociedad de consumo.

Se tiene a bien observar lo dicho por Galeano “...Lo que me pasa es que no consigo andar por el mundo tirando cosas y cambiándolas por el modelo siguiente sólo porque a alguien se le ocurre agregarle una función o achicarlo un poco. (...) Lo más probable es que lo de ahora esté bien, eso no lo discuto. Lo que pasa es que no consigo cambiar el equipo de música una vez por año, el celular cada tres meses o el monitor de la computadora todas las navidades. Es que vengo de un tiempo en el que las cosas se compraban para toda la vida. Es más ¡Se compraban para la vida de los que venían después! (...) ¿Cómo quieren que entienda a esa gente que se desprende de su celular a los pocos meses de comprarlo?”

En contexto, con el propósito de gestionar los desechos electrónicos, la ONU con el Programa de Medio Ambiente, la Agencia de Protección Ambiental de Estados Unidos, algunas Universidades del mundo y empresas como Dell, Microsoft, HP y Philips, crearon la iniciativa "Solucionar el problema de la basura". Este proyecto internacional ha buscado, entre otras cosas, homogenizar los procesos de reciclado en el mundo con el fin de que los componentes

\footnotetext{
${ }^{7}$ Antúnez Sánchez, A. (2018) El uso de las infotecnologías en la formación ambiental del ciudadano. Revista Derecho y Cambio Social No. 52, Perú. 
valiosos sean recuperados, vinculado a modo de ver por los autores del artículo, con los instrumentos económicos, como es la contabilidad ambiental. ${ }^{8}$

En consecuencia, ya se señalaba que algunos de los minerales que son encontrados en estos aparatos eléctricos y electrónicos son el litio, el cobre, el hierro, el aluminio, y el oro; materiales que pueden tras su recogida como materia prima para ser nuevamente utilizados y cuya extracción original llegará un día el momento en que se agoten. De aquí que se justiprecia que la actividad de la minería urbana tiene una serie de beneficios, al permitir evitar la dependencia del incremento de los precios de estas materias. Además, también se reducen las importaciones y se evita el agotamiento o escasez que se está comenzando a producir en determinadas materias primas en el mundo.

La minería urbana, se considera que permite incidir en el avance del concepto de EC ya que estas materias primas pueden volver de nuevo a utilizarse y tener otra vida útil en otros dispositivos u objetos como son los teléfonos celulares, en las computadoras, en televisores, etc. Otro de sus beneficios que se aprecian con la recuperación de materiales y el reciclado de metales en comparación con la minería en términos de uso de la tierra, de consumo de energía, emisión de sustancias peligrosas, generación de residuos y emisiones de dióxido de carbono (CO2), principal gas de efecto invernadero. Con la misma se aprecia que los sujetos de gestión que la aplique tendrán un valor agregado en su empresa, con ello serán más competitivos en el mercado.

Lo cual es observado desde su posición por Farbiarz Mas, al valorar desde el Derecho Internacional el Convenio de Basilea, sobre el control de los movimientos transfronterizos de los desechos peligrosos y su eliminación, al significar que es un tratado multilateral destinado a suprimir los patrones de comercialización de desechos peligrosos que son ambiental y

${ }^{8}$ PNUMA (2015) Descubriendo los caminos hacia una economía verde e inclusiva. Resumen ejecutivo. Ginebra. 
socialmente perjudiciales. ${ }^{9}$ Los desechos electrónicos, debido a su composición, a menudo contienen elementos peligrosos, la Convención afirma que, para proteger la salud humana y el medio ambiente, los desechos peligrosos no deben comercializarse libremente como los productos comerciales ordinarios, y, en consecuencia, establece un proceso de notificación y aprobación por escrito para todos los movimientos transfronterizos de desechos peligrosos. Pero la exención reglamentaria del Convenio de Basilea sobre equipos destinados a la reutilización es totalmente compatible con su principal objetivo ambiental para evitar la generación de residuos, ya que la reutilización prolonga el ciclo de vida de los AEE y, por lo tanto, mitiga la generación de residuos peligrosos, aquí se asevera por los autores del artículo su dimensión aplicativa.

Analizado este instrumento jurídico internacional, al prolongarse la funcionalidad de la electrónica, su reutilización promueve la conservación de los recursos naturales y al menos temporalmente desvía la necesidad de reciclaje o eliminación. Sin embargo, la distinción de si algo es un desperdicio o no y, por lo tanto, está destinado a ser reutilizado, ello es un debate de larga duración en el marco del Convenio de Basilea. La Conferencia de las Partes (COP 13) no pudo llegar a un consenso final. Se conceptualiza entonces, que la Minería Urbana (industria de reciclado electrónico), o minería inversa, a criterio de los autores tiene una dimensión normativa que pondere el principio de legalidad.

La obsolescencia programada u "obsolescencia planificada" a la programación del fin de la vida útil de un producto o servicio, de modo tal que tras un período de tiempo calculado de antemano por el fabricante o por la empresa durante la fase de diseño de dicho producto o servicio, éste se torne obsoleto, no funcional, inútil o inservible. Se ve claramente la

${ }^{9}$ Farbiarz Mas, A. (2018) Informe sobre tendencias de los RAEE a nivel mundial. Residuos Profesional. Disponible en: https://www.residuosprofesional.com/informe-tendencias-raee-nivel-mundial/ 
$\overline{\text { importancia de pensar la obsolescencia programada y los sistemas actuales de producción en el }}$ marco de una reflexión sobre el concepto de sostenibilidad. ${ }^{10}$

La economía verde es un sistema de actividades económicas relacionadas con la producción, distribución y consumo de bienes y servicios que resulta en mejoras del bienestar humano en el largo plazo, sin, al mismo tiempo, exponer las generaciones futuras a riesgos ambientales y escasez ecológicas significativas. ${ }^{11}$ Es caracterizada por un substancial aumento de las inversiones en sectores verdes, apoyadas por reformas políticas que sean instrumentales para esto. Estas inversiones ofrecen un mecanismo para la reingeniería de los negocios, de la infraestructura, de las instituciones y la adopción de procesos de producción y consumo sostenible. Dicha reingeniería conduce a una mayor participación de los sectores verdes en el Producto Interno Bruto, más y decentes empleos verdes, menor uso de energía y materiales en la producción, menor generación de desechos y contaminación y emisiones de gases de efecto invernadero muchas más bajas. Podemos entender a la economía verde, como aquella que incorpora al modo de producción actual variables medio ambientales y sociales, lo que no supone que esté directamente en contra de las ideas de libre mercado o de crecimiento como parte de los instrumentos económicos.

El concepto de "economía verde" queda claro que no sustituye al de "desarrollo sostenible", pero si es un camino para alcanzarlo. Por consiguiente, la economía verde se puede entender como un conjunto de modos de producción, donde se premia la búsqueda de maximizar la producción, tomando en consideración variables que son ignoradas a la hora de

\footnotetext{
${ }^{10}$ Consúltese, Gomes Bergstein, L. (2014) Obsolescencia programada: prática abusiva no mercado de consumo, Revista Jurídica da Faculdade de Direito Dom Bosco Nº 11, Brasil; Slade, G. (2006) Made to Break: Technology and Obsolescence in America, Harvard University Press, Cambridge.

${ }^{11}$ PNUMA (2011) Hacia una economía verde: guía para el desarrollo sostenible y la erradicación de la pobreza. Síntesis para los encargados de la formulación de políticas. New York.
}

Cienc. Soc. y Econ. UTEQ. 2020. 4(1): 109 - 153119 
establecer un negocio, como la conservación de los recursos naturales y la erradicación de la pobreza. $^{12}$

En consecuencia, se asevera que la relación entre crecimiento y el deterioro del medio ambiente es compleja, y depende de varias variables en evolución. Las más importantes son la evolución del tamaño de la población humana, el patrón de consumo (sobre todo de los países ricos) y una mezcla entre el nivel tecnológico y el uso que se haga de este, lo cual requiere inversiones públicas y privadas en $\mathrm{I}+\mathrm{D}+\mathrm{i}$ para mejorar la fabricación industrial, el mantenimiento, el control de calidad, la logística, y la distribución tecnológica con la implementación de la quinta generación $(5 \mathrm{G}){ }^{13}$

La economía lineal es un sistema de producción vigente que se basa principalmente en un proceso lineal de consumo de recursos. Bajo el paradigma "take-make-waste" (extraerfabricar-consumir-eliminar), los bienes son producidos a partir de las materias primas, luego vendidos, utilizados y finalmente desechados como residuos, lo que ocasiona no solo el agotamiento de los recursos naturales sino también la generación de toneladas de basura. ${ }^{14}$

En consecuencia, pueden identificarse las siguientes limitaciones al modelo lineal como los riesgos de precios: hacia finales del milenio los precios de los recursos naturales comenzaron a ascender y mientras la población crecerá, la urbanización se incrementará y los costos continuarán en aumento; y las pérdidas económicas y residuos estructurales: la economía actual genera una gran cantidad de residuos. En este contexto analizado, cada vez son más los que reclaman un cambio de modelo industrial que desvincule los ingresos del consumo de

\footnotetext{
${ }^{12}$ Martínez, A. y Porcelli, A. (2017) Reflexiones sobre la economía verde. El New Deal Ecológico Mundial. Revista de la Facultad de Derecho y Ciencia Política de la Universidad Alas Peruanas No ${ }^{\circ}$ 15, Perú. pp.361-408.

${ }^{13}$ Véase, Celaya, J. (2008) La empresa en la web 2.0, Editorial Gestión 2000, Barcelona; Torrent, J. (2008) La empresa red. Tecnologías de la información y la comunicación, productividad y competitividad, Editorial Ariel, España.

${ }^{14}$ Bauman, Z. (2004) Modernidad Líquida, Fondo de Cultura Económica, Buenos Aires, p.91

Cienc. Soc. y Econ. UTEQ. 2020. 4(1): $109-153120$
} 
materias primas y que sea capaz de ofrecer sistemas económicos resilientes: a ello apunta la economía circular como nuevo paradigma. ${ }^{15}$

La economía circular, en su evolución lógica en oposición a la lineal, el presente y el futuro del principio de desarrollo sostenible. Es cambiar del modelo lineal por uno circular, que devuelva lo que consideramos residuos a la categoría de materia prima y reutilizarlos hasta que realmente lo sean, es la esencia de ésta nueva estrategia. Es un paradigma que tiene como objetivo generar prosperidad económica, proteger el medio ambiente y prevenir la contaminación, facilitando así el desarrollo sostenible. Es por eso que este modelo se apoya en el principio de las 3 Rs (Reducir, Reusar, Reciclar), aplicable a todo el ciclo de vida de los productos. ${ }^{16}$

El origen de la Economía Circular (EC) no se remonta a una única fecha o un único autor como se ha podido constatar. Desde finales de la década de los 70' del pasado siglo, sus aplicaciones prácticas en los sistemas económicos y procesos industriales modernos han cobrado impulso, han ido desarrollándose a lo largo de este tiempo y continuará en el futuro del siglo XXI. La EC se define a partir de las siguientes características fundamentales: los residuos se eliminan del diseño (basura=alimento); la diversidad genera solidez y la energía necesaria para impulsar la economía circular debe ser de carácter renovable, para reducir la dependencia de los recursos e incrementar la resiliencia de los sistemas; pensar en sistemas: muchos elementos del mundo real, como empresas, personas o plantas, forman parte de sistemas complejos en los que las distintas partes están fuertemente vinculadas entre sí.

En la EC, estos vínculos se tienen en cuenta en todo momento; los precios deben decir la verdad: los precios u otros mecanismos de retroalimentación deben reflejar los costes reales

\footnotetext{
${ }^{15}$ García García, S. (2016) Economía circular: La Unión Europea impulsa reformas sobre la base de un tema crucial, la gestión de residuos, con el fin de alcanzar mejoras económicas y medioambientales. Revista Actualidad Jurídica Ambiental No. 57, España, pp. 1-11.

${ }^{16}$ Gudín Rodríguez-Magariños, F. (2019) Economía circular en la Unión Europea: un marco jurídico global para el Derecho medioambiental del siglo XXI, Editorial Las Rosaz, España.

Cienc. Soc. y Econ. UTEQ. 2020. 4(1): 109 - 153121
} 
ya que los precios actúan como mensajes; y reemplazo del concepto de consumidor por el de usuario: la EC trae aparejada una nueva relación entre los consumidores y las cosas. No es un concepto nuevo, aunque ha llamado la atención de la comunidad científica y empresarial en los últimos años, debido a su implementación como política estratégica para países desarrollados como Alemania, China, Japón, la Unión Europea, entre otros.

Hay que resaltar que en varios campos de estudio y disciplinas han sumado esfuerzos para impulsar el cambio del sistema económico lineal y clásico, al paradigma circular, algunas de ellas son: la Ciencia de la Administración, con el desarrollo de modelos de negocio alternativos y sostenibles; la Ingeniería, a través de la simbiosis industrial; el Diseño Industrial, con la estrategia "Cradle to Cradle" y la biomímesis, entre otros, de aquí que se pondere la transdisciplinariedad que tiene el tema que se aborda. También, puede afirmarse que la EC tiene como su gran aliada a las herramientas de las TIC y en especial a internet, ya que le permite la colaboración e intercambio de conocimiento más eficientes en la web 2.0, hoy potenciada a través de la quinta generación (5G). El uso de las TIC, las aplicaciones móviles y los sistemas de información geográfica (GPS) son algunos de los avances tecnológicos que posibilitan firmemente el surgimiento y el desarrollo de prácticas colaborativas. La EC hace referencia a prácticas de compartir e intercambio que desacoplan la posesión de un producto de su uso y suelen implicar la utilización de menos recursos. ${ }^{17}$

En este escenario estudiado emerge la EC, la que se puede conceptualizar por los materiales estudiados como una filosofía del diseño y de organización de sistemas. Inspirada en los seres vivos, emula con los ciclos de la naturaleza en la que los "desechos" de una especie se convierten en el "alimento" de otra y así sucesivamente en un sistema cíclico de autosuficiencia. Está concebida como un sistema industrial restaurador o regenerativo por intención y por diseño "ab initio", sustituye el concepto de "caducidad" por el de

\footnotetext{
${ }^{17}$ Valero Torrijos, J. (2004) Régimen Jurídico de la e-Administración. El uso de medios informáticos y telemáticos en el procedimiento administrativo, Editorial Comares, Granada.

Cienc. Soc. y Econ. UTEQ. 2020. 4(1): 109-153 122
} 
"restauración" distinguiendo entre ciclos técnicos y biológicos. Se desplaza hacia el uso de energías renovables, eliminando el uso de químicos tóxicos, que perjudican la reutilización y el retorno a la biosfera, es esta su finalidad para su aplicación por la Administración Pública.

Como se aprecia, la EC presenta una perspectiva ambiciosa, desafiante y más atrevida que la economía verde (una economía eficiente en recursos) puesto que requiere la transformación radical de los medios de producción, de las cadenas de suministro, de la cultura y de los hábitos de consumo a nivel planetario. En la EC, los recursos se regeneran dentro del ciclo biológico o se recuperan y restauran gracias al ciclos técnicos. Los componentes del ciclo biológico son biodegradables, por lo que se pueden introducir en la naturaleza después que su valor de uso ya no sea rentable. Los componentes de ciclos técnicos son poco aptos para volver de inmediato a la naturaleza, por lo que son reutilizados una y otra vez, aplicados dentro de la ciudad inteligente. ${ }^{18}$

No obstante, para la transición a una EC las empresas pueden adoptar diferentes acciones: regenerate (regenerar), share (compartir), optimise (optimizar), loop (bucle), virtualise (virtualizar) y exchange (intercambiar), que juntas conforman el marco Resolve (por las siglas de las iniciales de las palabras inglesas). También se resumen las medidas existentes en ecodiseño y ecoetiquetas, sobre todo en dispositivos electrónicos y anunció una Guía para la Transición hacia una EC en referencia a las Mejores Técnicas Disponibles para varios sectores industriales. ${ }^{19}$ De aquí que se valore que es el salto de lo que se pondera con las empresas responsables o amigables con el ambiente como también se les conoce. ${ }^{20}$

\footnotetext{
${ }^{18}$ Bouskela, M. et al. (2016) La ruta hacia las Smart Cities: Migrando de una gestión tradicional a la ciudad inteligente. Disponible en: https://publications.iadb.org/bitstream/handle/11319/7743/La-rutahacia-las-smart-cities-Migrando-de-una-gestion-tradicional-a-la-ciudad-inteligente.pdf

${ }^{19}$ Martínez, A. y Porcelli, A. (2018) El desafío del cambio económico: la economía circular y su excepción en las diferentes legislaciones y en la normativa voluntaria. Revista Pensar en Derecho N. ${ }^{\circ}$ 13, Colombia, pp.129-181

${ }^{20}$ Chamorro Mera, A. (2003) Tesis doctoral: El etiquetado ecológico, un análisis de su utilización como instrumento de marketing, Universidad de Extremadura, España.
} 
La EC supone un cambio radical de los sistemas de producción y consumo actuales. Esto evitará la creación de residuos e impactos negativos derivados, mitigando las externalidades negativas para el medio ambiente, el clima y la salud humana. Para el desarrollo sostenible, el objetivo ambiental de la EC es reducir el material virgen del sistema de producción-consumo y los insumos de energía y desechos y las emisiones (rendimiento físico) mediante la aplicación de ciclos de materiales y cascadas de energía basadas en energías renovables. ${ }^{21}$

El objetivo económico de la EC es reducir los costes de materias primas y energía del sistema de producción-consumo económico, gestión de residuos y costes de control de emisiones, riesgos de la legislación / imposición (medioambiental) e imagen pública, así como innovar diseños de nuevos productos y oportunidades de mercado para negocios. El objetivo social es la economía colaborativa, y el aumento del empleo (empleos verdes). ${ }^{22}$

Hay que resaltar que el concepto de EC viene de diversas fuentes referentes de la ecointeligencia. Abarca todas aquellas empresas, propósitos e iniciativas que manejan una economía sostenible, en el cual su objetivo desarrolle el valor de los productos materiales y sus recursos se conserven en el círculo económico durante el mayor tiempo posible. La finalidad es alargar la vida útil de los desperdicios, perfeccionándolos en recursos para formalizar una economía justa, social, colaborativa y sostenible, que deserte del actual sistema lineal de usar y tirar. Por ello, luego de haber abordado los elementos referenciados de mayor relevancia sobre la EC, se valora la pertinencia de la aplicación de la gestión de calidad y gestión ambiental bajo la observancia de las normas técnicas ISO 9001 y 14001, respectivamente. Y por supuesto bajo

\footnotetext{
${ }^{21}$ Sanz Larruga, F. (2016) Derecho Ambiental para una economía verde, Editorial Aranzadi, España. ${ }^{22}$ PNUMA, OIT, OIE, CSI (2008) Empleos verdes: Hacia el trabajo decente en un mundo sostenible y con bajas emisiones de carbono. Nairobi.
} 
la impronta del control público ambiental, a través de la función inspectiva y la auditora dentro de los instrumentos de gestión ambiental. ${ }^{23}$

\section{El Derecho Ambiental y la Minería urbana en el contexto del principio del desarrollo sostenible en pos de avanzar a la economía circular}

En la Conferencia de Rio de 1992 desde el plano internacional, es el momento en que aparece con fuerza la idea del "desarrollo sostenible". Veinte años después, aparece la idea de "economía verde", en la Conferencia de las Naciones Unidas del 2012. Es una necesidad alcanzar el desarrollo sostenible en el siglo XXI, desde el Informe "Nuestro Futuro Común" en 1984, se señala como el mega principio del Derecho Ambiental, el paradigma es cómo establecer políticas públicas para concretarlo. ${ }^{24}$

En consecuencia, se valora que alcanzar el principio del desarrollo sostenible es considerado en la actualidad como el paradigma más acuciante dentro del Derecho Ambiental, la lectura de la doctrina Hispanoamericana viene señalando que el desarrollo sostenible se encuentra en la base de la categoría de "instrumentos de mercado de carácter cooperador", que compatibilice la tutela ambiental con el crecimiento de la economía, de aquí la articulación del Derecho Administrativo Ambiental y en su evolución con la EC. Estos elementos valorados, se justiprecia que han permitido que se vaya consolidando como principio general del Derecho Administrativo Ambiental, a partir de la actualización de las técnicas jurídicas de tutela ambiental con la gestión ambiental compartida. ${ }^{25}$

En este sentido, se analiza el legado del profesor MARTín MATEO, el que en sus estudios sobre el mega principio -desarrollo sostenible- considera: el sector privado (incluidas las

\footnotetext{
${ }^{23}$ Antúnez Sánchez, A. \& Ramírez Sánchez, A. (2016) La potestad inspectiva v/s auditoría pública. Ojeada histórica dentro del Derecho Administrativo Ambiental cubano, Revista Dos Tribunais Thomsonreuters No.967, Brasil.

${ }^{24}$ Loperena Rota, D. (2003) Desarrollo sostenible y globalización, Editorial Thomson-Aranzadi, Argentina.

${ }^{25}$ Jordano Fraga, J. (2007) La Administración en el Estado Ambiental de Derecho, Revista de Administración Pública No. 173, España, pp.101-141.
} 
grandes empresas y las pequeñas) tiene el deber de contribuir a la evolución de comunidades y sociedades equitativas y sostenibles (Principio 24), y que las empresas del sector privado deben cumplir la obligación de rendir cuentas, en un entorno reglamentario, transparente y estable (Principio 26). ${ }^{26}$

En contexto, se aprecia que son dos puntos indispensables valorados por ser pertinentes para lograr alcanzar el desarrollo sostenible:

Primero, comprender que el crecimiento económico solo no basta para resolver los problemas del planeta: los aspectos económicos, sociales y ambientales de cualquier actividad están vinculados. Considerar únicamente uno de ellos a la vez da por resultado errores de juicio y de resultados insostenibles. Concentrarse sólo en los márgenes de utilidad, por ejemplo, históricamente ha causado daños sociales y ambientales que en el largo plazo le cuestan a la sociedad. Pero cuidar del ambiente y proporcionar los servicios que necesita la ciudadanía depende de los recursos económicos, al menos en forma parcial.

Segundo, la naturaleza intervinculada del desarrollo sostenible requiere que se trasciendan fronteras, ya sean geográficas o institucionales, para coordinar estrategias y tomar decisiones adecuadas. Los problemas rara vez están circunscritos a jurisdicciones definidas previamente como una dependencia del gobierno o un vecindario particular; y las soluciones inteligentes exigen que haya cooperación como parte del proceso decisorio.

Empero, en el núcleo del desarrollo sostenible se justiprecia que está en la necesidad de considerar los tres pilares juntos: la sociedad, la economía y el medio ambiente. En el plano jurídico, se valora que la idea fundamental del desarrollo sostenible es la vinculación entre el bienestar de la generación actual y el bienestar de las futuras generaciones. En ello, se aprecia que los sistemas de valores no han tomado en cuenta a la naturaleza y se han desbocado en una irracional carrera por el consumismo como estilo de vida y desarrollo sin una adecuada

\footnotetext{
${ }^{26}$ Martín Mateo, R. (1991) Tratado de Derecho Ambiental, $1^{\text {a }}$ edición, Editorial Trivium, España.
} 
responsabilidad ambiental por parte de los sujetos de gestión. El reto es desarrollar una sociedad ante los desafíos que se presentan para lograr el desarrollo sostenible como “...aquel que satisface las necesidades esenciales de la generación presente sin comprometer la capacidad de satisfacer las necesidades esenciales de las generaciones futuras... "27

\section{El Derecho Ambiental y el Derecho Minero}

Derecho Ambiental, como parte del sistema jurídico y rama de las ciencias jurídicas, su origen se ubica en la década de los 70' del siglo pasado a partir de la Cumbre en Estocolmo, comienza a introducirse la normativa ambientalista en el ordenamiento jurídico de un gran número de países, siendo el punto de conexión con el Derecho Internacional. Al que también se le denomina Derecho del Medio Ambiente o Derecho Ecológico, definido por diferentes autores desde perspectivas distintas como Martin Mateo; Brañes Ballesteros; Ortega Álvarez; Caferrata; De Besa Antunes, entre otros autores estudiosos de los temas ambientalistas. ${ }^{28}$

Por consiguiente, se asevera que el Derecho Ambiental, se caracteriza por tener relaciones con otras ramas del Derecho, donde en esta interrelación de carácter dialéctico, le aportan elementos que desarrollan tanto del Derecho Ambiental, como al resto de las ciencias jurídicas que se relacionan con él. Regula las conductas humanas con implicaciones ambientales, recoge conocimientos científicos que se han generado en el Derecho Internacional como génesis, con el Derecho Constitucional, con el Derecho Administrativo, Derecho Mercantil, Derecho Económico, Derecho Civil, Derecho Laboral, Derecho Financiero-Tributario, Derecho Agrario, Derecho de la Propiedad Industrial, entre otras; confiriéndosele una lectura distinta a la que

\footnotetext{
${ }^{27}$ Cruz Sardiñas, T. (2013) El derecho al desarrollo sostenible. Una actualización obligada para la doctrina del Derecho Ambiental, CITMA, La Habana.

${ }^{28}$ Véase para profundizar, Martín Mateo, R. (1991) Tratado de Derecho Ambiental, $1^{a}$ edición, Editorial Trivium, España; Brañes Ballesteros, R. (2003) La fundación del Derecho Ambiental en América Latina, PNUMA, Chile; Cafferata, N. (2004) Introducción al Derecho Ambiental, Editorial INESemarnat, México; Ortega Álvarez, L. (2012) Concepto de medio ambiente. Tratado de Derecho Ambiental, Editorial Tirant Lo Blanch, Valencia; De Besa Antunes, P. (2013) Direito Ambiental. Editorial Atlas. Brasil.
} 
otras ramas del Derecho pudieron haber hecho de los mismos, y luego de haberle dado el alcance que le corresponde, de acuerdo con su objeto los combina para formar un cuerpo nuevo y unificado que se materializan en el conjunto de categorías reguladas en el sistema normativo ambiental. Combina para formar un cuerpo nuevo y unificado que se materializan en el conjunto de categorías reguladas en el sistema normativo ambiental a través de un Código Ambiental. ${ }^{29}$

En consecuencia, aún y cuando el Derecho Ambiental se manifiesta a través de los actos jurídicos que le son propios, mucha de su normativa legal se encuentra dispersa en el resto de las ramas que conforman el sistema jurídico. Lo que se justifica atendiendo a que ninguna norma jurídica pertenece de una manera exclusiva y excluyente a una rama del Derecho determinada, consideradas bajo diferentes enfoques que son válidos tanto para el Derecho Ambiental como para otras disciplinas jurídicas que la contengan, pues no resulta factible fijar exactos límites entre ellas; realmente puede existir una zona común en sus fronteras. ${ }^{30}$

Al estudiarse la obra de la catedrática Jacquenod De Zsogön, considera al Derecho Ambiental como “...la disciplina jurídica que investiga, estudia y analiza las diferentes relaciones entre los bienes naturales y la actividad antrópica, orientando la relación jurídica de las conductas y actitudes humanas respecto al uso, explotación y aprovechamiento de recursos naturales, conservación de la naturaleza y protección del medio ambiente..." En este mismo argumento, sigue señalando “...sería aventurado afirmar que el derecho ambiental se perfila como una rama autónoma del ordenamiento jurídico, puesto que éste es un sistema de normas que no admite la existencia de regímenes totalmente separados; por tanto, adquiere relevancia en la medida en que se integra a un circuito de normas, a una interconexión progresiva de preceptos cuyo principia y fin es la construcción...” Además, tampoco podría decirse que

\footnotetext{
${ }^{29}$ Consúltese, Zeledón Zeledón, R. (1998) Código Ambiental, $11^{a}$ edición, Editorial Porvenir, San José; Parejo Alfonso, L. et al (2004) Código de Medio Ambiente, Editorial Thomson-Aranzadi, Cizur Menor, Navarra.

${ }^{30}$ Cañizares Abeledo, F. (1979) Teoría del Derecho, Editorial Pueblo y Educación, La Habana.

Cienc. Soc. y Econ. UTEQ. 2020. 4(1): 109-153 128
} 
forma parte de una rama especial del Derecho Público, ya que es difícil mantener la tradicional separación entre el régimen jurídico público y el privado debido a la infiltración de las instituciones jurídico-públicas en el régimen que rige las relaciones entre los particulares, y a una privatización de las reglas que presiden la organización y funcionamiento del Estado y sus instituciones. Para la autora estudiada, el Derecho Ambiental es definido como la disciplina jurídica que investiga, estudia y analiza las diferentes relaciones entre los bienes naturales y la actividad antrópica, orientando la regulación jurídica de las conductas y actitudes humanas respecto al uso, explotación y aprovechamiento de recursos naturales, conservación de la naturaleza y protección del ambiente Algunos autores consideran que el Derecho Ambiental es una rama autónoma del Derecho, debido a que cumple con los requisitos que suelen apuntarse como necesarios para considerar que una disciplina es autónoma. ${ }^{31}$

Desde el plano jurídico, se pondera que los elementos abordados son reforzados con el reconocimiento jurídico del pluralismo jurídico De Jure, al otorgarse derechos a la naturaleza como sujeto, la pacha mama dentro del sumak kuasay en los textos constitucionales de Bolivia y Ecuador en la región de América Latina, como referentes en sus cartas políticas de este siglo XXI, lo diferencian con otras naciones donde el Derecho Ambiental tiene un mayor desarrollo dentro del concepto del buen vivir. ${ }^{32}$

Implica, a criterio de los autores del artículo la necesidad de construir un nиеvo concepto de naturaleza, superar su imagen cosificada como res extensa instaurada por el derecho positivo moderno; de una naturaleza susceptible de ser manipulada, sometida, dominada, controlada, explotada. Se trata de sustituir los principios inconmovibles e inamovibles del Derecho Privado, por un proceso abierto al juego de valores e intereses sobre

\footnotetext{
${ }^{3 l}$ Confróntese, Jaquenod De Zsogon, S. (1991) El Derecho Ambiental y sus principios rectores, Editorial Dykinson, Madrid; Jaquenod de Zsogon, S. (2004) Derecho Ambiental, información, investigación, $2^{\mathrm{a}}$ edición, Editorial Dykinson, Madrid.

${ }^{32}$ Schavelzon, S. (2015) Plurinacionalidad y vivir bien/buen vivir. Dos conceptos leídos desde Bolivia y Ecuador post-constituyentes, Editorial Adya-Yala, Quito.
} 
la conservación, uso y transformación de la naturaleza, con procedimientos jurídicos flexibles para dirimir conflictos de intereses contrapuestos y para alcanzar un bien público basado en el reconocimiento de sus diferencias, en este caso del Derecho occidental.

El Derecho Ambiental, al estudiar lo ponderado por los autores estudiados en la revisión bibliográfica, se arguye que hay similitudes en ponderar que no es sólo el conjunto de normas que aseguran el uso controlado de la naturaleza, sino aquel que regula los intereses en conflicto en torno a las estrategias diferenciadas de apropiación de sus recursos, donde se inscriben los derechos territoriales y culturales de los pueblos. El derecho a un ambiente sano es fundamental porque es humano. Significa que su valor fundamental no tiene fuente distinta a su consustancialidad con el ser humano, que, forjado en un crisol de avatares biológicos, históricos, sociales y axiológicos, irremediablemente perdería su condición humana si fuese despojado de sus derechos fundamentales, a partir de su reconocimiento entre los derechos de solidaridad. ${ }^{33}$

El Derecho Minero representa la delegación que el Estado hace al privado de la operación de los recursos naturales, en este caso de las minas. Tiene que ser un acto expreso proveniente del Estado, que se materializa a través de una concesión minera. Es aquel que el Estado expresamente delega al particular, mediante el cual le brinda un derecho personal a conducir actividades mineras por intermedio de un título minero, que debe seguir ciertas solemnidades, tales como su inscripción en el registro minero. Así mismo, este título tiene restricciones en cuanto se refiere a la libertad de transferencia, puesto que es el Estado quien debe autorizar expresamente dicho acto. ${ }^{34}$

La actividad minera, como la gran mayoría de las acciones humanas, ocasiona daños inmediatos a la naturaleza, sin embargo, es una importante fuente de obtención de riquezas que

\footnotetext{
${ }^{33}$ Véase, Rosa Moreno, J. (2000) El Derecho Ambiental en Latinoamérica, Editorial McGraw-Hill, Madrid; Peña Chacón, M. et al. (2019) Derecho Ambiental del siglo XXI, $1^{\text {a }}$ edición, Editorial Isolma, Costa Rica.

${ }^{34}$ Junceda Moreno, J. (2001) Minería, Medio Ambiente y Ordenación del territorio, Editorial Civitas, Madrid.
} 
contribuyen al logro de la sustentabilidad. Para adentrarnos en la minería urbana, tenemos a bien abordar de primer orden al Derecho Minero, quien para autores como GAY BARBOSA y González señalan “...ordenamiento jurídico autónomo que con contenido económico y político, regula las relaciones jurídicas de los sujetos intervinientes directa o indirectamente en toda la actividad de exploración, adquisición, producción, explotación, comercialización, transformación y aprovechamiento de recursos naturales no renovables estableciendo derechos, obligaciones y procedimientos en armonía con la naturaleza con el objeto de obtener el abastecimiento y beneficios a distribuir equitativamente entre los distintos sectores intervinientes y el desarrollo integral de la sociedad..."35

En su expresión en el ordenamiento jurídico, con contenido económico y político, regula las relaciones jurídicas de los sujetos intervinientes directa o indirectamente en toda la actividad de exploración, adquisición, producción, explotación, comercialización, transformación y aprovechamiento de recursos naturales no renovables estableciendo derechos, obligaciones y procedimientos en armonía con la naturaleza con el objeto de obtener el abastecimiento y beneficios a distribuir equitativamente entre los distintos sectores intervinientes y el desarrollo integral de la sociedad.” Regula las relaciones jurídicas de los sujetos intervinientes directa o indirectamente en toda la actividad de exploración, adquisición, producción, explotación, comercialización, transformación y aprovechamiento de recursos naturales no renovables estableciendo derechos, obligaciones y procedimientos en armonía con la naturaleza con el objeto de obtener el abastecimiento y beneficios a distribuir equitativamente entre los distintos sectores intervinientes y el desarrollo integral de la sociedad. El dominio público según el régimen general del dominio público señala las consecuencias de la demanialización y los objetivos que debe perseguir, esta ley ha de proceder no sólo a su separación del régimen general de Comercio si no queda de proporcionar a la categoría de

\footnotetext{
${ }^{35}$ Gay Barbosa, D. et al. (2014) Conceptos de Derecho Minero, Universidad Blas Pascal, Perú. Cienc. Soc. y Econ. UTEQ. 2020. 4(1): 109-153 131
} 
bienes un régimen jurídico adaptado a esas necesidades que se proponen conseguir. Régimen que debes suponer la adaptación de los principios inspiradores a esta categoría de bienes. Sobre ello también se ha reconocido la competencia del Estado para proceder a su regulación como un mecanismo de restricción a su acceso y de cumplimiento de sus fines en relación con el derecho de la minería. Es la consecuencia lógica de haber sacado los bienes el comercio indicando que constituyen el rasgo más característico del dominio público y la nota que proyecta más consecuencias para el tráfico de estos bienes. La más inmediata es que los bienes de dominio público, mientras tengan el carácter de bien público, no se puede ni realizar por parte de los entes públicos ningún acto traslativo de dominio tenga la forma jurídica que tenga compraventa, donación o cualquiera otra ya sea este puro, condicional o a plazo. Es una consecuencia directa de que esté fuera del comercio de los recursos minerales. ${ }^{36}$

\section{La actividad minera en Cuba. Regulación en el ordenamiento jurídico}

Para su mejor comprensión de la actividad minera en la nación cubana, será analizada por etapas, a partir de la diversidad de procesos tecnológicos extractivos, relacionados con la recuperación de oro, cobre, plata, plomo y zinc, a partir de sus yacimientos minerales principales. En tal sentido, estos procesos extractivos provocan cambios de tipo ambiental y social, que es preciso tener en cuenta en el momento de diseñar políticas ambientales. Cuba, como nación tiene una larga trayectoria minera dado sus recursos que posee.

En la Colonia Española desde 1511-1898 la llegada de los conquistadores españoles, como referente histórico, los profesores Torres-Cuevas y Loyola-Vega, señalan que los nativos de los pueblos originarios practicaban la llamada minería recolectora con la obtención de pepitas de oro directamente de los aluviones de los ríos. Permite justipreciar que, aunque los aborígenes cubanos reconocían los ríos como los sitios idóneos para su recolección, no es hasta

\footnotetext{
${ }^{36}$ García, J. (2013) Los Bienes de Derecho Público. Editorial Foreword. España.
}

Cienc. Soc. y Econ. UTEQ. 2020. 4(1): 109 - 153132 
la llegada de los conquistadores que en Cuba existió una verdadera actividad minera. ${ }^{37}$ La etapa inicial de la colonización se caracterizó por la extracción de oro, hecho histórico que ocurre en las zonas geográficas de la nación en Bayamo, Jobabo, Guáimaro, Arimao, Agabama y Jaruco. $^{38}$

Con la neo colonia desde 1902-1958 la pequeña minería del oro en Cuba se centró fundamentalmente en la región de Villa Clara y en Holguín, siendo esta última la de mayor importancia para el país. Aunque, hay que significar que la actividad minera en Cuba, se aprecia como comienza a desarrollarse a partir del 1902, al incrementarse la extensión de la mina "El Cobre", en la localidad del mismo nombre, y con ello comenzar la explotación de hierro y manganeso en la región oriental. Posteriormente, comenzó la explotación del yacimiento de Matahambre en la antigua provincia de Pinar del Río (explotada desde 1913 hasta 1997). En la década del 40' del pasado siglo, se comienza la explotación de laterita para la extracción de níquel más cobalto y otros minerales. ${ }^{39}$

Esta actividad extractivista, estimulada por el desarrollo de la Revolución industrial inglesa, se aprecia como la minería del cobre experimentó en Cuba un importante crecimiento en el segundo tercio del siglo XIX. Como consecuencia, la isla se convirtió en uno de los grandes productores mundiales de mineral. Aunque, el ciclo del cobre cubano del XIX fue relativamente breve: se inició en torno a 1830 y puede darse por finalizado en 1868 , como se asevera en referentes históricos estudiados. ${ }^{40}$

\footnotetext{
${ }^{37}$ Torres-Cuevas, E. y Loyola-Vega, O. (2001) Historia de Cuba 1492-1898. Formación y liberación de la nación, Editorial Pueblo y Educación, La Habana.

${ }^{38}$ Vgr. Torres-Cuevas, E. y Loyola-Vega, O. (2001) Historia de Cuba 1492-1898. Formación y liberación de la nación

${ }^{39}$ Soto-González, L.D. (1981) Apuntes sobre la historia de la minería cubana, Editorial Oriente, Santiago de Cuba.

${ }^{40}$ Consúltese para profundizar, Salterain, P. (1883) Breve reseña de la minería de la isla de Cuba, Editorial La Publicidad, La Habana; Franco, J. L. (1975) Las minas de Santiago del Prado y la rebelión de los cobreros, 1575-1800, Editorial de Ciencias Sociales, La Habana; D Soto González, L. (1981) Apuntes sobre la historia de la minería cubana, Editorial Oriente, Santiago de Cuba.
} 
Queda reflejado de esta manera que, la minería en Cuba se reguló dentro del ordenamiento jurídico con la promulgación de la Ley de Minas de 1859 y el Decreto Ley de Bases Generales para la Nueva Legislación de Minas de 1868, así como con más de 20 cuerpos jurídicos que hasta el año 1966 regularon la política jurídica en materia de Derecho Minero por el Estado, lo refleja la historia de la nación cubana. ${ }^{41}$

A partir de 1959 se parte de la preocupación y ocupación del Estado cubano en cuanto a la protección de los recursos naturales, consagrada en la Constitución de la República de $1976 .{ }^{42}$

Para ello se realiza un análisis del texto constitucional desde el pasado siglo XX hasta el actual milenio de su reconocimiento en el ordenamiento jurídico:

\begin{tabular}{|c|c|c|}
\hline 1 & Constitución de la República de Cuba de 1976. & $\begin{array}{l}\text { Artículo 15: La propiedad estatal socialista, } \\
\text { que es la propiedad de todo el pueblo, se } \\
\text { establece irreversiblemente sobre las tierras } \\
\text { que no pertenecen a los agricultores } \\
\text { pequeños o a cooperativas integradas por los } \\
\text { mismos; sobre el subsuelo, las minas, los } \\
\text { recursos marítimos naturales y vivos dentro } \\
\text { de la zona de su soberanía, los bosques, las } \\
\text { aguas, las vías de comunicación; sobre los } \\
\text { centrales azucareros, las fábricas, los medios } \\
\text { fundamentales de transporte, y cuantas } \\
\text { empresas, bancos, instalaciones y bienes han } \\
\text { sido nacionalizados y expropiados a los } \\
\text { imperialistas, latifundistas y burgueses, así } \\
\text { como sobre las granjas del pueblo, fábricas, } \\
\text { empresas e instalaciones económicas, } \\
\text { sociales, culturales y deportivas construidas, } \\
\text { fomentadas o adquiridas por el Estado y las } \\
\text { que en el futuro construya, fomente o } \\
\text { adquiera. } \\
\text { Artículo 27: El Estado protege el medio } \\
\text { ambiente y los recursos naturales del país. } \\
\text { Reconoce su estrecha vinculación con el }\end{array}$ \\
\hline
\end{tabular}

\footnotetext{
${ }^{41}$ Guerrero, D. La industria minera en Cuba. Área minera. El sitio de la minería. Disponible en: hptt//:www.areaminera.com

${ }^{42}$ Pérez Hernández, L. y Prieto Valdés, M. et al. (2002) Temas de Derecho Constitucional Cubano, $2^{\text {da }}$ edición, Editorial Félix Varela, La Habana, 2002
} 
Volumen 4, Número 1. Semestral (enero-junio)

\begin{tabular}{|c|c|c|}
\hline & & $\begin{array}{l}\text { desarrollo económico y social sostenible. } \\
\text { Para hacer más racional la vida humana y } \\
\text { asegurar la supervivencia, el bienestar y la } \\
\text { seguridad de las generaciones actuales y } \\
\text { futuras }\end{array}$ \\
\hline 2 & $\begin{array}{l}\text { Modificación a la Constitución de la República } \\
\text { de Cuba de } 1976 \text { realizada en } 1992 .\end{array}$ & $\begin{array}{l}\text { Artículo 15: Son de propiedad estatal } \\
\text { socialista de todo el pueblo: } \\
\text { a) las tierras que no pertenecen a los } \\
\text { agricultores pequeños o a cooperativas } \\
\text { integradas por éstos, el subsuelo, las minas, } \\
\text { los recursos naturales tanto vivos como no } \\
\text { vivos dentro de la zona económica marítima } \\
\text { de la República, los bosques, las aguas y las } \\
\text { vías de comunicación; } \\
\text { Artículo 27: El Estado protege el medio } \\
\text { ambiente y los recursos naturales del país. } \\
\text { Reconoce su estrecha vinculación con el } \\
\text { desarrollo económico y social sostenible } \\
\text { para hacer más racional la vida humana y } \\
\text { asegurar la supervivencia, el bienestar y la } \\
\text { seguridad de las generaciones actuales y } \\
\text { futuras. Corresponde a los órganos } \\
\text { competentes aplicar esta política. } \\
\text { Es deber de los ciudadanos, contribuir a la } \\
\text { protección del agua, la atmósfera, la } \\
\text { conservación del suelo, la flora, la fauna y } \\
\text { todo el rico potencial de la naturaleza. }\end{array}$ \\
\hline 3 & $\begin{array}{l}\text { Modificación a la Constitución de la República } \\
\text { de Cuba de } 1976 \text { realizada en } 2003 \text {. Gaceta } \\
\text { Oficial Extraordinaria No. 3, de fecha } 31 \text { de } \\
\text { enero } 2003\end{array}$ & $\begin{array}{l}\text { Artículo 15: Son de propiedad estatal } \\
\text { socialista de todo el pueblo: } \\
\text { a) las tierras que no pertenecen a los } \\
\text { agricultores pequeños o cooperativas } \\
\text { integradas por éstos, el subsuelo, las minas, } \\
\text { los recursos naturales tanto vivos como no } \\
\text { vivos dentro de la zona económica marítima } \\
\text { de la República, los bosques, las aguas y las } \\
\text { vías de comunicación; } \\
\text { Artículo 27: El Estado protege el medio } \\
\text { ambiente y los recursos naturales del país. } \\
\text { Reconoce su estrecha vinculación con el } \\
\text { desarrollo económico y social sostenible } \\
\text { para hacer más racional la vida humana y } \\
\text { asegurar la supervivencia, el bienestar y la } \\
\text { seguridad de las generaciones actuales y }\end{array}$ \\
\hline
\end{tabular}




\begin{tabular}{|c|c|c|}
\hline & & $\begin{array}{l}\text { futuras. Corresponde a los órganos } \\
\text { competentes aplicar esta política. } \\
\text { Es deber de los ciudadanos contribuir a la } \\
\text { protección del agua, la atmósfera, la } \\
\text { conservación del suelo, la flora, la fauna y } \\
\text { todo el rico potencial de la naturaleza. }\end{array}$ \\
\hline 5 & $\begin{array}{l}\text { Constitución de la República de Cuba de } 2019 \text {. } \\
\text { Gaceta Oficial Extraordinaria No. 5, de fecha } 10 \\
\text { de abril de } 2019\end{array}$ & $\begin{array}{l}\text { Artículo 11: el Estado ejerce soberanía y } \\
\text { jurisdicción, } \\
\text { inciso b) sobre el medio ambiente y los } \\
\text { recursos naturales del país } \\
\text { Artículo 16: las relaciones internacionales de } \\
\text { Cuba, } \\
\text { inciso f) promueve la protección y } \\
\text { conservación del medio ambiente y el } \\
\text { enfrentamiento al cambio climático, que } \\
\text { amenaza la sobrevivencia de la especie } \\
\text { humana, sobre la base del reconocimiento de } \\
\text { responsabilidades comunes, } \\
\text { diferenciadas; el establecimiento de un orden } \\
\text { económico internacional justo y equitativo y } \\
\text { la erradicación de los patrones irracionales } \\
\text { de producción y consumo } \\
\text { Artículo 23: Son de propiedad socialista de } \\
\text { todo el pueblo: las tierras que no pertenecen } \\
\text { a particulares o a cooperativas integradas por } \\
\text { estos, el subsuelo, los yacimientos minerales, } \\
\text { las minas, los bosques, las aguas, las playas, } \\
\text { las vías de comunicación y los recursos } \\
\text { naturales tanto vivos como no vivos dentro } \\
\text { de la zona económica exclusiva de la } \\
\text { República. } \\
\text { Artículo 28. El Estado promueve y brinda } \\
\text { garantías a la inversión extranjera, como } \\
\text { elemento importante para el desarrollo } \\
\text { económico del país, sobre la base de la } \\
\text { protección y el uso racional de los recursos } \\
\text { humanos y naturales, así como del respeto a } \\
\text { la soberanía e independencia nacionales. } \\
\text { Artículo 75: Todas las personas tienen } \\
\text { derecho a disfrutar de un medio ambiente } \\
\text { sano y equilibrado. El Estado protege el } \\
\text { medio ambiente y los recursos naturales del } \\
\text { país. Reconoce su estrecha vinculación con }\end{array}$ \\
\hline
\end{tabular}




\begin{tabular}{|l|l|l|}
\hline $\mid$ & $\begin{array}{l}\text { el desarrollo sostenible de la economía y la } \\
\text { sociedad para hacer más racional la vida } \\
\text { humana y asegurar la supervivencia, el } \\
\text { bienestar y la seguridad de las generaciones } \\
\text { actuales y futuras. } \\
\text { Artículo 90: El ejercicio de los derechos y } \\
\text { libertades previstos en esta Constitución } \\
\text { implican responsabilidades. Son deberes de } \\
\text { los ciudadanos cubanos, además de los otros } \\
\text { establecidos en esta Constitución y las leyes: } \\
\text { inciso j) proteger los recursos naturales, la } \\
\text { flora y la fauna y velar por la conservación } \\
\text { de un medio ambiente sano. }\end{array}$ \\
\hline
\end{tabular}

Conllevó a continuar el estudio concomitante del ordenamiento jurídico de los cuerpos legales vinculantes a la protección de los recursos naturales, en especial de la minera.

\begin{tabular}{|l|l|l|}
\hline 1 & $\begin{array}{l}\text { Ley No. 41, Ley de la Salud Pública, Gaceta } \\
\text { Oficial Ordinaria No.61 de fecha 15 de agosto de } \\
1983\end{array}$ & $\begin{array}{l}\text { Tiene el mandato de prestar la asistencia } \\
\text { médica de manera gratuita, y de manera } \\
\text { especialidad tratar las enfermedades } \\
\text { profesionales, producto de enfermedades } \\
\text { contraídas por la actividad minera. }\end{array}$ \\
\hline 2 & $\begin{array}{l}\text { Ley No. 59, Código Civil, Gaceta Oficial } \\
\text { Extraordinaria No. 9 de fecha 15 de octubre de } \\
1987\end{array}$ & $\begin{array}{l}\text { Todo derecho, incluido el de propiedad, } \\
\text { debe ejercerse de acuerdo a su contenido } \\
\text { social y finalidad, conforme a su destino } \\
\text { socioeconómico (artículo 129), de modo } \\
\text { racional (artículo 132), y dentro de los } \\
\text { límites generalmente admitidos } \\
\text { artículo170.2). De modo más preciso, } \\
\text { refiriéndose específicamente a la protección } \\
\text { del ambiente como límite al derecho de } \\
\text { propiedad, se reconoce de forma explícita a } \\
\text { lo dispuesto en la legislación ambiental, pues } \\
\text { en el artículo 131.1, faculta al propietario del } \\
\text { terreno para que haga en él obras, } \\
\text { plantaciones y excavaciones, con las } \\
\text { "limitaciones" establecidas en las } \\
\text { disposiciones legales, haciendo especial } \\
\text { referencia a las relativas a la "...protección } \\
\text { del patrimonio nacional y cultural, y a los } \\
\text { recursos naturales y el medio ambiente". En } \\
\text { segundo apartado del propio precepto obliga } \\
\text { al titular del predio a adoptar las mayores }\end{array}$ \\
\hline
\end{tabular}




\begin{tabular}{|c|c|c|}
\hline & & $\begin{array}{l}\text { precauciones a fin evitar todo “...peligro, } \\
\text { daño, contaminación o perjuicio a las } \\
\text { personas o a los bienes" }\end{array}$ \\
\hline 3 & $\begin{array}{l}\text { Ley No. 76, Ley de Minas, Gaceta Oficial } \\
\text { Ordinaria No. } 3 \text { de } 23 \text { de enero de } 1995\end{array}$ & $\begin{array}{l}\text { Artículo 4: Al Estado le corresponde el } \\
\text { dominio inalienable e imprescriptible del } \\
\text { subsuelo, las minas y todos los recursos } \\
\text { minerales, donde quiera que éstos se } \\
\text { encuentren, dentro de las regulaciones } \\
\text { constitucionales. } \\
\text { Artículo 22: Las concesiones son de } \\
\text { investigación geológica, de explotación o de } \\
\text { procesamiento. Los trabajos de } \\
\text { reconocimiento no requieren del } \\
\text { otorgamiento de concesiones, siendo objeto } \\
\text { de permisos por el Ministerio de la Industria } \\
\text { Básica. }\end{array}$ \\
\hline 4 & $\begin{array}{l}\text { Ley No. 81, Ley de Medio Ambiente, Gaceta } \\
\text { Oficial Extraordinaria No.7 de fecha } 11 \text { de julio } \\
\text { de } 1997\end{array}$ & $\begin{array}{l}\text { Artículo 120: El aprovechamiento de los } \\
\text { recursos minerales por cualquier persona } \\
\text { natural o jurídica se regirá por las } \\
\text { disposiciones siguientes: } \\
\text { a) la actividad minera estará sujeta al } \\
\text { proceso de evaluación de impacto ambiental, } \\
\text { por lo que el concesionario solicitará la } \\
\text { licencia ambiental para ejecutar la fase de } \\
\text { investigación geológica y estará obligado a } \\
\text { solicitar la licencia ambiental y a elaborar el } \\
\text { estudio de impacto ambiental, cuando } \\
\text { corresponda, en las fases de explotación y } \\
\text { procesamiento; } \\
\text { b) la actividad minera deberá causar la } \\
\text { menor alteración posible, directa o indirecta, } \\
\text { al Sistema Nacional de Áreas Protegidas, las } \\
\text { aguas terrestres y marítimas, la capa vegetal, } \\
\text { la flora y la fauna silvestre, el paisaje y al } \\
\text { medio ambiente en general. } \\
\text { Artículo 122: Las personas naturales o } \\
\text { jurídicas que desarrollan actividades de } \\
\text { aprovechamiento de recursos minerales, } \\
\text { estarán en la obligación de rehabilitar las } \\
\text { áreas degradadas por su actividad, así como } \\
\text { las áreas y ecosistemas vinculados a éstas } \\
\text { que puedan resultar dañados, de } \\
\text { conformidad con lo dispuesto en la Ley de } \\
\text { Minas y en la presente Ley, o en su defecto, }\end{array}$ \\
\hline
\end{tabular}




\begin{tabular}{|c|c|c|}
\hline & & $\begin{array}{l}\text { a realizar otras actividades destinadas a la } \\
\text { protección del medio ambiente, en los } \\
\text { términos y condiciones que establezcan el } \\
\text { Ministerio de Ciencia, Tecnología y Medio } \\
\text { Ambiente, el Ministerio de la Agricultura y } \\
\text { el Ministerio de la Industria Básica. }\end{array}$ \\
\hline 5 & $\begin{array}{l}\text { Ley No. 113, Ley del Sistema Tributario. Gaceta } \\
\text { Oficial Ordinaria No. } 53 \text { de } 21 \text { de noviembre de } \\
2012\end{array}$ & $\begin{array}{l}\text { Artículo 238: Se regulan bajo el presente } \\
\text { Título los tributos por el uso o explotación } \\
\text { de playas, bahías, recursos forestales y el } \\
\text { vertimiento de residuales en cuencas } \\
\text { hidrográficas que tributan a las bahías y por } \\
\text { el uso de aguas terrestres, que tienen como } \\
\text { fin la conservación y cuidado de los } \\
\text { ecosistemas y recursos naturales que resulten } \\
\text { dañados. (impuesto ambiental) }\end{array}$ \\
\hline 6 & $\begin{array}{l}\text { Ley No. } 116 \text { de 2013, Código de Trabajo. Gaceta } \\
\text { Oficial No. } 29 \text { Extraordinaria de } 17 \text { de junio de } \\
2014\end{array}$ & $\begin{array}{l}\text { Establece la relación jurídica laboral en la } \\
\text { actividad de la minería, y también regula el } \\
\text { sistema de protección e higiene en el trabajo } \\
\text { en relación al uso de los medios de } \\
\text { protección en el desarrollo de la actividad } \\
\text { minera. }\end{array}$ \\
\hline 7 & $\begin{array}{l}\text { Ley No. 118. Ley de la Inversión Extranjera. } \\
\text { Gaceta Oficial Extraordinaria No. } 20 \text { de } 16 \text { de } \\
\text { abril de } 2014\end{array}$ & $\begin{array}{l}\text { Cuerpo legal que permite realizar } \\
\text { inversiones a extranjeros a través de una } \\
\text { empresa mixta o contrato de asociación } \\
\text { económica internacional, en contratos a } \\
\text { riesgo para la exploración de recursos } \\
\text { naturales no renovables. Artículo } 13.2\end{array}$ \\
\hline
\end{tabular}

En el siglo XXI se continúa el análisis de la postura de la catedrática Cutie Mustelier, quien refiere sobre este texto constitucional de 2019, que actualiza, completa, amplia de manera significativa y sustancial el catálogo de derechos, se logra una ordenación coherente y sistémica, evitando la dispersión o atomización de estos por la preceptiva constitucional, al agruparlos bajo el rótulo de derechos sin adjetivos o sea elimina el calificativo de fundamentales y les confiere a todos los derechos igual jerarquía y valor pues todos independientemente de su naturaleza, de la generación a la que pertenecen y de las clasificaciones de orden metodológico e histórico que existen, son universales, indivisibles e 
interdependientes y están situados al mismo nivel, o sea ningún derecho es más importante que otro.

Prosigue la autora estudiada que, este texto constitucional declara el principio de progresividad de los derechos, con lo que se deja sentado, la condición evolutiva de los mismos, es decir la tabla de derechos no es un catálogo cerrado, sino que estos se ensanchan y amplían con el desarrollo de la sociedad, quedando la Constitución abierta a la recepción de nuevos derechos y a la interpretación y actualización del contenido esencial de los mismos a tono con las nuevas demandas y exigencias de la sociedad, el desarrollo legislativo de los derechos y la creación por parte del Estado de las condiciones materiales necesarias para su real disfrute y ejercicio. Refiere que se delinea y especifica en mejor medida los límites al ejercicio de los derechos, al establecer como fronteras, los derechos de los demás, la seguridad colectiva, el bienestar general, el respeto al orden público, a la Constitución y a las leyes. A su vez, introduce nuevos derechos o los llamados derechos de tercera generación tales como: el derecho al acceso a la información pública y a recibir información veraz, objetiva y oportuna, el derecho al agua, a la alimentación sana y adecuada, a la vivienda adecuada y a un hábitat seguro y saludable, el derecho al medio ambiente sano y equilibrado, y el derecho de los consumidores. ${ }^{43}$ Como se aprecia, prevalece el dominio del sector público en materia de Derecho Minero en el ordenamiento jurídico nacional,

Siendo válido aclarar que, como nota distintiva, en el ordenamiento jurídico de Cuba, el sistema contravencional, proveniente del Derecho Administrativo, ocupa el lugar predominante de todas las formas de exigencia de responsabilidad ambiental. No solo por la pluralidad de disposiciones jurídicas en cuerpos de Decretos Leyes y Decretos, sino por la variedad de esferas de protección ambiental vinculadas a la protección de los recursos minerales, en especial a la extracción de minerales, conocido dentro de la materia como Derecho Minero.

\footnotetext{
${ }^{43}$ Cutie Mustelier, D. (2019) ¿Por qué la Nueva Constitución cubana es Superior? Red Jurídica UNJC, La Habana. Disponible en: hptt://www.unjc.cu
} 
$\overline{\text { Demuestran estos elementos estudiados por los autores del artículo que en el siglo XX en el }}$ ordenamiento jurídico cubano fueron promulgadas una serie de normas jurídicas dirigidas a la protección de los recursos naturales vinculadas al Derecho Minero, ello es otra nota a destacarse desde el plano jurídico.

Aunque hay que significar que existen normas jurídicas y normas técnicas que de forma complementaria regulan a los procedimientos de tratamiento de los residuos y evidencian el postulado del principio de prevención y legalidad. En el entramado de la Administración Pública nacional, se aprecia cómo se ha constituido una empresa que se ocupa de la recogida y el reciclaje de las materias primas. Aquí en esta actividad de recolección participan sujetos privados y cooperativas, los que recogen en las ciudades los desechos metálicos y no metálicos objeto de compraventa por la aludida empresa (aluminio, hierro, cobre, bronce, entre otros), bajo precios establecidos por el Ministerio de Finanzas y Precios. Pero la norma jurídica ausente es la "Ley de Reciclaje", donde queden clarificados los elementos abordados en el cuerpo del artículo.

\section{Conclusiones}

La Declaración de Johannesburgo sobre el Desarrollo Sostenible en el 2002, acepta de manera expresa "la realidad de que la sociedad mundial tiene los medios y recursos para responder a los retos" planteando para superar la supuesta dicotomía entre protección ambiental y desarrollo económico por la vía de armonizar ambos procesos, hoy sin una adecuada armonía que permita la protección ambiental en atención a los Objetivos del Milenio propuestos para el 2030.

La cumbre Río+20, del 2012, sobre el paradigma del desarrollo sostenible, se avanzó en el logro de una "economía verde" en el contexto del desarrollo sostenible y la erradicación de la pobreza, y el marco institucional para el desarrollo sostenible, pero se necesita avanzar a mayor celeridad para revertir los efectos adversos al ambiente.

Cienc. Soc. y Econ. UTEQ. 2020. 4(1): 109 - 153141 
La Minería urbana o Minería inversa tiene su génesis en el Derecho Minero y este desde el Derecho Administrativo Ambiental, ha variado y evolucionado en el tiempo, tiene un enfoque multidisciplinar desde su reconocimiento a partir del plano jurídico desde el Derecho Internacional, contextualizada su regulación en los textos constitucionales. Se ha desarrollado en los ordenamientos jurídicos a través de contenidos que integran desde el Derecho Administrativo, el Derecho Ambiental, el Derecho Mercantil, el Derecho Tributario, la Informática Jurídica, el Derecho Económico, el Derecho Laboral, el Derecho a la Seguridad y Salud laboral, entre otras, como dimensión normativa. Desde su dimensión transdisciplinaria se aprecia estar vinculada con la Historia, la Economía, la Contabilidad ambiental, las Ciencias Ambientales, la Ingeniería Ambiental, las Matemáticas, entre otras disciplinas y saberes.

El modelo de Economía Circular se dirige hacia un nuevo paradigma con la Minería Inversa, implica una nueva modalidad de hacer productos desde su mismo origen, desde su diseño, y permite hacer negocios atendiendo al crecimiento económico de la sociedad, a la sustentabilidad ambiental y a la disminución de los riesgos por la volatilidad e incertidumbre de precios de las materias primas y recursos energéticos. Es avanzar hacia una reconciliación con la naturaleza como continuidad del desarrollo sostenible, como parte de las políticas sociales, culturales, ambientales y económicas de la sociedad.

El ejercicio de la Minería Urbana o Inversa no se establece en el ordenamiento jurídico cubano el uso de normas jurídicas que dispongan los procedimientos legales tales como la tramitación de licencias ambientales, su fiscalización y control; esta es realizada por sujetos privados que se dedican a la recolecta de residuos sólidos en las ciudades y los comercializan en establecimientos de la empresa de materia primas por un precio fijado por el Estado. Lo que tributa de alguna manera a la higienización de las ciudades y territorios en pos del desarrollo sustentable desde la economía circular. 
La gestión ambiental ejecutada por los actores económicos públicos y privados en Cuba deberá estar enfocada a cumplir el principio de legalidad bajo las normas técnicas ISO 9001 y 14001, necesitado de una actualización de la Ley Ambiental, la promulgación de una Ley de Empresas y una Ley de Competencias en el ordenamiento jurídico cubano, donde se pondere la observación de la Economía Circular través de iniciativas que manejan una economía sostenible, donde se perfeccione el uso de recursos para formalizar una economía justa, social, colaborativa y sostenible, que deserte del actual sistema lineal de usar y tirar, en atención a la dimensión económica, política, tecnológica y sociocultural en la actualización del nuevo modelo económico y social.

El control público tendrá un elemento a ponderar en las actividades mineras ejecutada por los órganos de control del Ministerio de Ciencias, Tecnología y Medio Ambiente y la Contraloría General de la República; ello exige de un profesional con amplios conocimientos, requiriendo una capacitación técnica y permanente de los agentes económicos afectados, y de un conocimiento amplio de las regulaciones legales y aspectos técnicos del proceso de la auditoría, que permita certificar la calidad ambiental como empresa responsable con el ambiente como su finalidad.

La llegada del siglo XXI ha caracterizado el símbolo de la reconfiguración global de la cultura humana, señalada por una oleada de innovaciones tecnológicas sin precedentes en la historia. En el mundo el crecimiento de la contaminación ambiental en las ciudades, vinculada con el incremento del uso de dispositivos electrónicos en cifras significantes, los que una vez lleguen al final de su vida útil la población desconoce los términos como Minería urbana, Minería inversa, Economía circular por su impacto socio ambiental al poner en riesgo la salud humana, estando necesitados de formación jurídica ambiental.

La universidad en su responsabilidad como mandato constitucional con la formación jurídica ambiental, el presente le exige educar para innovar e innovar para educar como Cienc. Soc. y Econ. UTEQ. 2020. 4(1): $109-153143$ 
protagonistas en nuevos modelos donde el hombre actué de manera responsable en la protección ambiental como es el tema del artículo sobre la Minería Inversa o Urbana, y que lo haga con las competencias requeridas, ello tributará a alcanzar la armonía y el equilibrio adecuado entre el desarrollo industrial, los avances tecnológicos y la protección al ambiente.

\section{Referencias bibliográficas}

AA. VV. (2007) Derecho Ambiental cubano, Editorial Félix Varela, La Habana.

Abdel, G. \& Romo, D. (2004) Sobre el concepto de competitividad. Serie de documentos de trabajo en estudios de competitividad, Editorial ITAM, México.

Antúnez Sánchez, A. y Ramírez Sánchez, A. (2016) La potestad inspectiva v/s auditoría pública. Ojeada histórica dentro del Derecho Administrativo Ambiental cubano, Revista Dos Tribunais Thomsonreuters N. 967, Brasil.

Antúnez Sánchez, A. y Díaz Ocampo, E. (2018) La responsabilidad social y medio ambiental de la empresa: una perspectiva desde Cuba, Revista Responsabilidad Social Empresarial, España.

Álvarez Conde, J. (1957) Historia de la geología, mineralogía y paleontología en Cuba, (s.e.) La Habana.

Ballesteros, J. y Pérez Adán, J. (1997) Sociedad y medio ambiente. Editorial Trotta, Madrid.

Brañes Ballesteros, R. (2003) La fundación del Derecho Ambiental en América Latina, PNUMA, Chile.

Bellorio Clabot, D. (2013) El nuevo paradigma ambiental y jurídico, V Foro ambiental Internacional, Argentina.

Bellorio Clabot, D. (2004) Tratado de Derecho Ambiental, 1ª edición, Editorial Astrea, Buenos Aires.

Bustamante Alsina, J. (2010) Derecho Ambiental, Editorial Abeledo Perrot. Argentina.

Botassi, C. (1997) Derecho Administrativo Ambiental, Editorial Platense, Argentina. 
Brundtland, G. (1987) Informe Nuestro futuro Común, ONU.

Cafferatta, N. (2004) Los principios y reglas del Derecho Ambiental. PNUMA. El Salvador.

Cánovas González, D. (2011) Estudios sobre Derecho del Ambiente, Editorial Hermanos Vadell, Caracas.

Cánovas González, D. (2010) Licencia ambiental y sistemas de responsabilidad, El Derecho Público en Cuba a comienzos del siglo XXI, Editorial de la Universidad de La Habana.

Caraballo Maqueira, L. (2014) El Derecho Ambiental. Realidades y esperanzas, Editorial Acuario, La Habana.

Callejón, M. (2007) I+D innovación y política pública: hacia una nueva política económica de innovación, Revista sobre la Sociedad del Conocimiento No ${ }^{\circ}$, España.

Catalán Sender, J. (2001) Urbanismo y minas, licencias municipales, planeamiento y tributos locales, Editorial Bayer hermanos, España.

Conceptualización del modelo económico y social cubano de desarrollo socialista, $7^{\circ}$ congreso del Partido Comunista de Cuba (2016) Editorial Política, La Habana.

Centeno, R. (1977) Principios del Derecho Minero. Fundación Gómez Pardo. Madrid.

CEPAL (2018) Agenda 2030. Los Objetivos de Desarrollo Sostenible. Una oportunidad para América Latina y el Caribe, Chile.

Da Silva, A. (2005) Direito do meio ambiente e dos recursos naturais, Editorial RT, São Paulo.

De Guillebon, B. (2014) Los 7 Pilares de la Economía Circular. Boletín de la Confederación de Empresarios de Navarra No 21 Medio Ambiente, España, pp. 4-5.

De Besa Antunes, P. (2013) Direito Ambiental. Editorial Atlas. Brasil.

De Arcenegui, I. (2002) Derecho Minero, Editorial Civitas, Madrid.

Diez de Velasco, M. (2009) Instituciones de Derecho Internacional Público. 17 ${ }^{\mathrm{a}}$ edición. Editorial Tecnos, España. 
Diez-Picazo, L. (1954) Naturaleza jurídica de los minerales. ¿Tienen o no la condición de frutos? Editorial Librería A \& M Jiménez, Madrid.

Dios Vietiez, M. (2015) Recursos mineros y ordenación del territorio, Editorial Atelier, España.

Dromi, R. (2001) Derecho Administrativo. 9a edición actualizada. Editorial de Ciencia y Cultura. Argentina.

D’ Estéfano Pisani, M. (1996) Derecho Ambiental Internacional, Editorial Ciencias Sociales, La Habana.

Díaz Legón, O. et al (2016) Apuntes sobre la Ley $N^{o}$. 113, Del Sistema Tributario, en el marco de las transformaciones económicas en Cuba. Estudios Jurídicos, Editorial Loynaz, Pinar del Río.

Di Cagno, V. et al. (2005) La protección del medio ambiente en Cuba, Editorial Ciencias Sociales, La Habana, Cuba.

Escalabaltra, E. (1965) El dominio del Estado sobre las minas, Santiago de Chile.

Esteve Pardo, J. (2014) Lecciones de Derecho Administrativo. Editorial Marcial Pons, $4^{\mathrm{a}}$ edición, España.

Franco Ferrán, J. (1975) Las minas de Santiago del Prado y la rebelión de los cobreros, 1575 1800, Editorial Ciencias Sociales, La Habana.

Fernández Protomastro, G. (2013) Minería urbana y la gestión de los recursos electrónicos, $1^{\text {a }}$ edición, Editorial Grupo Uno, Buenos Aires.

Fernández Rubio-Legra, Á. (1999) Derecho Ambiental Internacional, Editorial AFR, La Habana.

Fernández-Rubio Legrá, Á. (1999) Ley $N^{o} .81$ en más de 150 preguntas y respuestas, Editorial MINJUS, La Habana. 
Fernández-Rubio Legrá, Á. (2000) La legislación ambiental contemporánea: logros y fracasos, algunas reflexiones críticas, Editorial Academia, La Habana.

Fernández De Gatta Sánchez, D. (2010) El régimen jurídico de las evaluaciones de impacto ambiental, las evaluaciones estratégicas y las auditorías ambientales, Documento TOL 1.436.850, España.

Fernández De Gatta Sánchez, D. (2008) Derecho Ambiental, Editorial Trivium, España.

Figueras, M. (1992) La industrialización en Cuba, Editorial Ciencias Sociales, La Habana.

Harlem Burtland, G. (1984) Informe Nuestro Futuro Común, ONU.

Hauriou, M. (1925) Principios de Derecho Administrativo y de Derecho Público. $10^{a}$ edición. Editorial Recueil Sirey. Paris.

Hoowr, T. (1946) Economía Minera, Editorial Fondo de Cultura Económica. México.

Herrera Molina, P. (2000) Derecho tributario ambiental. Editorial Marcial Pons, España.

Gay Barbosa, D. et al. (2014) Conceptos de Derecho Minero, Universidad Blas Pascal, Perú.

García García, S. (2016) Economía circular: La Unión Europea impulsa reformas sobre la base de un tema crucial, la gestión de residuos, con el fin de alcanzar mejoras económicas y medioambientales. Revista Actualidad Jurídica Ambiental №. 57, España, pp.1-11.

García, J. (2013) Los Bienes de Derecho Público. Editorial Foreword. España.

García Cortes, A. (2005) Minería y Desarrollo Sostenible, Instituto Geológico y Minero de España, Madrid.

García Fernández, J. y Rey Santos, O. (2005) Foros de negociación e instrumentos jurídicos internacionales en materia de medio ambiente y desarrollo sostenible, Editorial Acuario. La Habana.

Garcini Guerra, H. (1986) Derecho Administrativo, Editorial Pueblo y Educación, La Habana.

Galindo Camacho, M. (2000) Teoría de la Administración Publica, Editorial Porrúa, México. 
Gordillo, A. (2014) Tratado de Derecho Administrativo y obras selectas, Fundación Derecho Administrativo, Argentina.

Gudín Rodríguez-Magariños, F. (2019) Economía circular en la Unión Europea: un marco jurídico global para el Derecho medioambiental del siglo XXI, Editorial Las Rosaz, España.

Guaita. A. (1986) Derecho Administrativo, Aguas, Montes, Minas, 2ª edición, Editorial Civitas, Madrid.

Real Ferrer, G. (2016) Residuos y sostenibilidad. El modelo europeo. Revista Aranzadi de Derecho Ambiental. № 35, España.

Rey Santos, O. et al. (2017) La Ley de medio ambiente: 20 años después, Editorial UNIJURIS, La Habana.

Rey Santos, O. (2013) Fundamentos del Derecho Ambiental, Editorial CIABO, La Habana.

Rebollo Puig, M. (2010) Derecho Administrativo sancionador, Editorial Lex Nova, España.

Rojas Orozco, C. (2003) El desarrollo sustentable: nuevo paradigma para la administración pública, Editorial INAP, México.

Rodríguez, C. (2014) Manual de Derecho Minero. Universidad Externado de Colombia. Bogotá.

Rosa Moreno, J. (2000) El Derecho Ambiental en Latinoamérica, Editorial McGraw-Hill, Madrid.

Rodrigo, A. J. (2015) El desafío del desarrollo sostenible. Los principios del Derecho Internacional relativos al desarrollo sostenible, Editorial Marcial Pons, Madrid.

Lastres Berninzon, E. (2007) Derecho de Minería y Energía, 1a edición, Editorial Primer Fuente, Perú.

Leff, E. et al. (1991) Las ciencias sociales y la formación ambiental a nivel universitario en América Latina. UNESCO, México. 
Lorenzetti, R. (2011) El paradigma ambiental, Ministerio de la Corte Suprema, Argentina.

Lorenzetti, R. (2008) Teoría del Derecho Ambiental, Editorial Porrúa, México.

Loperena Rota, D. (2003) Desarrollo sostenible y globalización, Editorial Thomson-Aranzadi, Argentina.

López Menudo, F. (2012) El derecho a la protección del medio ambiente, Universidad de Sevilla, España.

Lozano Cutanda, B. (2014) Tratado de Derecho Ambiental. Editorial CEF. España.

Libro Verde sobre la responsabilidad social empresarial (2011) Bruselas.

Libro Blanco de responsabilidad ambiental (2000) España.

Libro Verde sobre la gestión de los biorresiduos en la Unión Europea (2008) España.

Le Riverend, J. (1971) Historia Económica de Cuba, Editorial Instituto Cubano del Libro, La Habana.

Martín Mateo, R. (1991) Tratado de Derecho Ambiental, $1^{\text {a }}$ edición, Editorial Trivium, España. Martínez, A. y Porcelli, A. (2017) Reflexiones sobre la economía verde. El New Deal Ecológico Mundial. Revista de la Facultad de Derecho y Ciencia Política de la Universidad Alas Peruanas N ${ }^{0} \cdot 15$, Perú.

Martínez, A. y Porcelli, A. (2018) El desafío del cambio económico: la economía circular y su excepción en las diferentes legislaciones y en la normativa voluntaria. Revista Pensar en Derecho N. ${ }^{\circ} 13$, Colombia, pp.129-181

Martínez, V. (1982) Derechos Reales en la minería, Editorial Depalma, Argentina.

Martín-Retortillo Báquer, S. (2006) Derechos fundamentales y medio ambiente, Universidad Complutense de Madrid, España.

Marienhoff, M. (1965) Tratado de Derecho Administrativo, Editorial Abeledo-Perrot, Argentina.

Mayer, O. (1949) Derecho Administrativo alemán, Editorial Depalma, Argentina. 
Milaré, E. (2011) Direito do Ambiente. Editora Revista dos Tribunais. Brasil

Moreno Plata, M. (2010) Génesis, evolución y tendencias del paradigma del desarrollo sostenible, Editorial Porrúa, México.

Moreu Carbonell, E. (2001) Minas. Régimen jurídico de las actividades extractivas, Editorial Tirant lo Blanch, Valencia.

Muñoz Machado, M. (2011) Tratado de Derecho Administrativo y Derecho Público General, Contratos del sector público. Editorial Iustel, España.

Meier, H. (2003) El Derecho Ambiental y el nuevo milenio, $1^{\text {a }}$ edición, Editorial Homero, Caracas.

Parada, R. (1997) Derecho Administrativo, 9ª edición, Editorial Marcial Pons, España.

Parejo Alfonso, L. (2013) Lecciones de Derecho Administrativo, orden económico y sectores de referencia, Editorial Tirand Lo Blanch, España.

Parejo Alfonso, L. (2013) El derecho al medio ambiente y la actuación de la Administración Pública, Editorial Aranzadi, España.

Pigretti, E. (1976) Manual de Derecho minero y de la energía. Cooperadora de derecho y ciencias sociales, Argentina.

Pigretti, E. (1997) Código de Minería y Legislación de Hidrocarburos comentado. Editorial Abeledo-Perrot. Argentina.

Pigretti, E. (2004) Derecho Ambiental Profundizado, Editorial La Ley, Buenos Aires.

Pigretti, E. (1965) Teoría jurídica de los recursos naturales, Editorial Platense, Buenos Aires.

Piñar Mañas, J. (2003) El desarrollo sostenible como principio jurídico, Estudios de Derecho Público económico, Madrid, pp.185-204

Pierri, N. (2005) Historia del concepto desarrollo sustentable. ¿Sustentabilidad? Desacuerdos sobre el desarrollo sustentable. Cámara de Diputados México, pp. 27-81. 
Peña Chacón, M. et al. (2019) Derecho Ambiental del siglo XXI, $1^{\text {a }}$ edición, Editorial Isolma, Costa Rica.

PNUMA. Hacia una economía verde: guía para el desarrollo sostenible y la erradicación de la pobreza. Síntesis para los encargados de la formulación de políticas. New York, 2011.

PNUMA. Descubriendo los caminos hacia una economía verde e inclusiva. Resumen ejecutivo. Ginebra, 2015.

Prieur, M. (1991) Droit de l'environnement. Editorial Dalloz, Paris.

Triana, A. (1995) Código de Minas, Compilado y Concordado. 2a edición, Editorial Leyer, Colombia.

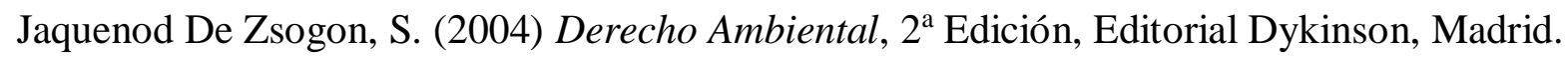

Jáimez, M. (2000) Titularidades privadas sobre minas y minerales. Editorial Tirant Monografías, España.

Jordano Fraga, J. (2008) Un desafío para los ordenamientos en el siglo XXI: el desarrollo sostenible. QDL. Fundación Democracia y Gobierno Local. España.

Juste Ruíz, J. (2005) El Desarrollo Sostenible y los Derechos Humanos, Protección Internacional de los Derechos Humanos: Nuevos desafíos, Editorial Porrúa, México.

Juste Ruiz, J. (1999) Derecho Internacional del Medio Ambiente, Editorial Mac Graw Hill, Madrid.

Junceda Moreno, J. (2001) Minería, medio ambiente y ordenación del territorio, Editorial Civitas, Madrid.

Jinesta Lobo, E. (2007) Tratado de Derecho Administrativo, Editorial Jurídica Continental, Costa Rica.

Uribe Herrera, A. (1968) Manual de Derecho de minería, $3^{\text {a }}$ edición, Santiago de Chile. Sánchez Morón, M. (2010) Derecho Administrativo, 6ª edición, Editorial Tecnos, España. 
Sanz Rubiales, I. (2000) Sobre la naturaleza jurídica de la etiqueta ecológica, Editorial Marcial Pons, España, pp.7-19.

Sanz Rubiales, I. (2012) El mercado de los derechos a contaminar, Editorial Lex Nova, España.

Saenz, O. (2007) Las ciencias ambientales: una nueva área de conocimiento, Editorial Digiprint, Colombia.

Sanz Larruga, F. (2016) Derecho Ambiental para una economía verde, Editorial Aranzadi, España.

Schavelzon, S. (2015) Plurinacionalidad y vivir bien/buen vivir. Dos conceptos leídos desde Bolivia y Ecuador post-constituyentes, Editorial Adya-Yala, Quito.

Soriano Garcia, J. y Brufao Curiel, P. (2010) Claves de Derecho Ambiental, $1^{\mathrm{a}}$ edición, Editorial Iustel, España.

Soler Del Sol, A. (2013) El Derecho al alcance de todos, Ley No.81. Ley del Medio Ambiente, Editorial ONBC, La Habana.

Ossa, J. (2007) Tratado de Derecho de Minería. Editorial Jurídica de Chile. Santiago.

Ortega Álvarez, L. (2012) Concepto de medio ambiente. Tratado de Derecho Ambiental, Editorial Tirant lo Blanch, Valencia.

Triana, A. (1995) Código de Minas, Compilado y Concordado. $2^{\mathrm{a}}$ edición, Editorial Leyer, Bogotá.

Triay León, A. (1951) Derechos Reales, volumen II, $3^{\text {ra }}$ edición, Editorial Librería Martí, La Habana.

Tunkin, G. (1979) Curso de Derecho Internacional, Editorial Progreso, Moscú.

Quintana López, T. (2013) Concesión de minas y medio ambiente, Editorial Tirand Lo Blanch, España. 
Kelsen, H. (1980) Teoría Pura del Derecho y Teoría Ecológica, Revista de Derecho UNAM. México.

Valls, M. (2008) Derecho Ambiental, $5^{\text {ta }}$ edición, Editorial Abeledo Perrot, Argentina.

Vergara Blanco, A. (2011) Principios y Sistemas del Derecho Minero. Estudio históricodogmático, Editorial Jurídica de Chile, Santiago de Chile.

Vergara Blanco, A. (2010) Instituciones de Derecho Minero. Editorial Thomson Reuters-Legal Publishing. Chile.

Verdes/Ale (2015) La Economía Circular, un cambio de paradigma para todos. Bruselas.

Villa, H. (2015) Derecho Internacional Ambiental. Editorial Astrea. Medellín.

Zamora Roselló, M. (2018) La energía de los residuos: un paso más en la economía circular. Servicios de interés general y protección de los usuarios (educación, sanidad, servicios sociales, vivienda, energía, transportes y comunicaciones electrónicas). Editorial Dykinson. España, pp. 395-410.

Zeballos De Sisto, M. (2000) El Derecho Ambiental Internacional: Esquema de su evolución, Editorial Estudio, Argentina. 